\title{
Urbanization effect on the observed changes of surface air temperature in Northeast China
}

\author{
Xiangjin Shen ${ }^{1, *}$, Yang Liu ${ }^{1}$, and Binhui Liu $^{2}$ \\ ${ }^{1}$ Northeast Institute of Geography and Agroecology, Chinese Academy of Sciences, Changchun, China \\ ${ }^{2}$ College of Forestry, The Northeast Forestry University, Harbin, China
}

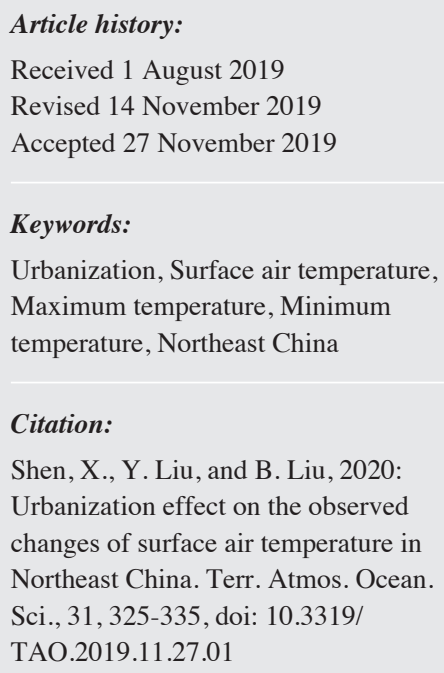

Citation:

Shen, X., Y. Liu, and B. Liu, 2020: Urbanization effect on the observed changes of surface air temperature in Northeast China. Terr. Atmos. Ocean. Sci., 31, 325-335, doi: 10.3319/ TAO.2019.11.27.01

\begin{abstract}
Although many studies have analyzed the effects of urbanization on temperature changes, the urbanization's effect on temperature change remains controversial. Northeast China is the largest old industrial base in China, which experienced a rapid urbanization in the past decades. Under the background of climate change, understanding the changes of surface air temperature and urbanization effects on temperature changes in the Northeast China is important to predict climate change in China. By analyzing the historical climate data, our results suggested that minimum temperature (Tmin) over the Northeast China increased significantly $\left(0.40^{\circ} \mathrm{C}\right.$ decade $\left.^{-1}\right)$ from 1960 to 1989 , but showed no significant change $\left(-0.02^{\circ} \mathrm{C}\right.$ decade $\left.{ }^{-1}\right)$ during 1990 - 2016. Due to slight change of maximum temperature (Tmax), the diurnal temperature range (DTR) showed a significant decreasing trend before $1989\left(-0.34^{\circ} \mathrm{C}\right.$ decade $\left.^{-1}\right)$, but reached a stable level after $1990\left(-0.06^{\circ} \mathrm{C}\right.$ decade $\left.^{-1}\right)$. In Northeast China, urbanization had a significant warming effect on Tmin during the night-time, but had different effects on Tmax during the daytime under the different changes of solar radiation before and after 1990. There were moderate warming effects of urbanization on Tmax during the solar dimming period of 1960 - 1989, but weak cooling effects on Tmax during the solar stable period after 1990. Due to obvious warming effect of urbanization on Tmin, urbanization in Northeast China tends to result in an increase of mean temperature but a decrease of DTR.
\end{abstract}

\section{INTRODUCTION}

The global mean temperatures increased about $0.74^{\circ} \mathrm{C}$ during the last century, and the increasing greenhouse gas concentrations is widely considered as the primary reason (e.g., Karl et al. 1993; Li et al. 2010; Wang and Dickinson 2013). Besides the greenhouse gas, there are some other factors, such as atmospheric circulations, solar radiation, precipitation, urbanization, and aerosols that can also change the surface air temperatures by affecting the surface energy and hydrological balance (Dai et al. 1997, 1999; Liu et al. 2004; Wild et al. 2007; Ren et al. 2008; Zhou et al. 2009; Shen et al.2014). Although many studies have analyzed the possible effects of these factors on temperature changes, the urbanization's effect on temperature change remains controversial. For example, many studies have found significant effect of urbanization on global or regional temperature

\footnotetext{
* Corresponding author

E-mail: shenxiangjin@iga.ac.cn
}

change (Portman 1993; Zhou et al. 2004; Ren et al. 2008; Sun et al. 2016); but there are also many studies suggested that the effects of urbanization on temperature changes were not obvious (Jones et al. 1990; Easterling et al. 1997; Li et al. 2004; Hansen et al. 2010). Due to the complexity of the climatology, further investigations on the effects of urbanization on temperature changes are still needed.

China is one of the most rapidly urbanizing countries during the past decades in the world. Many studies found significant impacts of urbanization on temperatures in China (Wang et al. 1990, 2013; Zhou et al. 2004; Hua et al. 2008; Yang et al. 2011; Cao et al. 2016a, b; Chen and Frauenfeld 2016; Sun et al. 2016). On the contrary, the weak effects of urbanization on temperatures were also reported in some regions of China and the country as a whole ( $\mathrm{Li}$ et al. 2004). Based on the solar radiation data, some studies pointed out that solar radiation in China changed from dimming since the 1960s to brightening after 1990 (Ye et 
al. 2010; Wang et al. 2012). Wang et al. (2012) found that the impacts of urbanization on temperatures in China were different under the solar dimming and brightening. During the solar dimming period, they found that Tmax in both urban and rural stations of China showed a weak decreasing trend, and Tmin in all stations showed significant warming trends. Due to urbanization effect, the increasing trend of Tmin was much larger in urban stations than that in rural stations (Wang et al. 2012). During the solar brightening period, however, both Tmax and Tmin increased dramatically in all stations of China. Different from the dimming period, Tmax increased faster in rural stations, and the Tmin showed a comparable increasing rate in urban and rural stations during the solar brightening period. They argued that due to urban anthropogenic aerosols, the brightening could be much stronger in rural places than in urban places, which accounted for the faster increasing Tmax in rural areas during the solar brightening period (Wang et al. 2012). Although many studies have analyzed the changes of solar radiation in China based on solar radiation data, the quality of solar radiation data obtained in China is often doubted (Shi et al. 2008). By using the data of sunshine duration (SD), a good proxy for analyzing solar irradiance change, Shen et al. (2014) found that solar radiation in China changed from dimming to a stable level after 1990 . This result was consistent with Tang et al. (2011) who investigated the solar radiation changes in China by combining quality-controlled solar radiation data and radiation models. In order to further understand the urbanization effects on temperature in China, the influences of urbanization on temperature change during the different periods of solar radiation changes should be further investigated.

Northeast China is the largest old industrial base of China, which has experienced a rapid urbanization during the past decades. In this study, using temperature records from 60 weather stations during 1960 - 2016, we analyzed the changes of temperatures in Northeast China and explored the effects of urbanization on temperature change by comparing the temperatures in the urban and surrounding rural stations. Considering the possible effects of solar radiation changes, the effects of urbanization on temperature changes were compared during different periods of solar radiation changes. Understanding the changes of temperature and the effects of urbanization on temperature changes is important to predict future climate change in China.

\section{METHODOLOGY}

Northeast China $\left(38-53^{\circ} \mathrm{N}\right.$ and $\left.115-135^{\circ} \mathrm{E}\right)$ is an old industrial base with high urbanization level in China, and it includes three provinces of Heilongjiang, Jilin and Liaoning, as well as northeastern part of Inner Mongolia autonomous region (Zhang 2008; Ren et al. 2012; Shen et al. 2017). During the past decades, however, economic development in Northeast China lagged behind the eastern coastal cities of China, and the rate of regional urbanization slowed down. Since 1978, with the development of the reforms and opening-up of China, Northeast China has experienced a tough reconstruction process (Su et al. 2014). In terms of climatic conditions, most of the Northeast China has a temperate monsoon climate, which is characterized by cold and long winter, as well as warm and short summer (Shen et al. 2019a, b). The annual mean temperature in Northeast China is about -1 to $6^{\circ} \mathrm{C}$, which is usually lower than that in the same latitudes of the world (Du et al. 2013). The annual precipitation in Northeast China is about 400 $1000 \mathrm{~mm}$, and the precipitation is mainly concentrated in summer (Sun et al. 2007).

Data used in this study included daily mean temperature (Tmean), maximum temperature (Tmax), minimum temperature (Tmin) and sunshine duration (SD) data over the Northeast China during 1960 - 2016. We used the method proposed by Wang and Gaffen (2001) to assure the quality and consistency of climatic data, following the procedure described in our previous studies (Shen et al. 2014, 2018). It is inevitable that there are missing data for the weather stations that have a long-term monitoring of weather conditions. The proportion of missing data across all the original meteorological data is about $0.29 \%$, and the most gaps are less than 3 days. Consistent with previous studies (Liu et al. 2004; Shen et al. 2014), this study adopted a simple linear interpolation algorithm to fill the missing temperature data when these missing data were less than 7 consecutive days. In addition, we used a stepwise regression to supply the missing data if the missing data were more than 7 consecutive days. For these missing data, we performed the stepwise regression per 5 years and set all the data that have no missing data as the variable. Finally, we compared the gap-filled dataset with the original dataset, and found that there were no statistically significant $(p<0.05)$ differences of means or trends between these two datasets. Therefore, the gap-filled data in this study will not affect the results of this study especially considering its very tiny percentage of all the data.

In this study, the trends of temperatures were estimated by Mann-Kendall test and simple linear regression (Mann 1945; Kendall 1975). In addition, the effects of urbanization on the changes of temperatures in Northeast China were explored by comparing the temperatures between urban and rural weather stations (Ren et al. 2008; Wang et al. 2012). According to the standard practice in many previous studies ( $\mathrm{Li}$ et al. 2010, 2015; Wang et al. 2012), we used the urban population of the area where the stations are located to divide the stations into urban stations (the population is more than 500000) and rural stations (the population is less than 500000) in Northeast China. The population data used in this study came from the Fifth National Population Census provided by the National Bureau of Statistics of China 
(http://www.stats.gov.cn/english/). To reduce the effect of topography and geography on the results, 30 pairs of urban and rural stations were selected to investigate the urbanization effect in this study (Fig. 1).

This study used the sunshine duration (SD) data as a proxy for analyzing solar irradiance changes, and found that solar radiation in China changed from dimming to a stable level after 1990 (Fig. 2). As a result, the whole study period of 1960 - 2016 can be divided into two sub-periods. One is during 1960 - 1989 and the other is during 1990 - 2016, which represents the dimming and no significant changes times, respectively. Based on previous studies that found different urbanization impacts on temperatures under the solar dimming and brightening, we further compared the urbanization effects on temperatures during the solar dimming period with that during the solar stable period in this study.

\section{RESULTS}

During 1960 - 2016, long-term average annual Tmean, Tmax, Tmin, and DTR over the whole Northeast China were $5.17,11.29,-0.33$, and $11.62^{\circ} \mathrm{C}$, respectively. The long-term average annual Tmean, Tmax, and Tmin were larger for urban stations $\left(5.46,11.51\right.$, and $0.04^{\circ} \mathrm{C}$, respectively) than that for rural stations $\left(4.88,11.07\right.$, and $-0.70^{\circ} \mathrm{C}$, respectively) (Fig. 3). Because the temperature difference between urban and rural stations was lager for Tmin than Tmax, long-term average DTR was smaller in urban stations $\left(11.47^{\circ} \mathrm{C}\right)$ than that in rural stations $\left(11.77^{\circ} \mathrm{C}\right)$. During two different periods of 1960 - 1989 and 1990 - 2016, we also found larger long-term average annual Tmean, Tmax, and Tmin, but smaller DTR for urban stations (Table 1).

Consistent with the changes of $\mathrm{SD}$, the temporal changes of temperatures in Northeast China showed different regimes before and after 1990 (Fig. 4). Over the Northeast China, Tmean and Tmin increased significantly from 1960 to 1989 , but showed no significant changes during 1990 - 2016 (Fig. 4). Due to slight changes of Tmax during these two different periods, the diurnal temperature range (DTR) showed a significant decreasing trend before 1989, but reached a stable level after 1990 (Fig. 4d). During the whole study period of 1960 - 2016, annual Tmean, Tmax, and Tmin increased significantly by $0.30,0.19$, and $0.41^{\circ} \mathrm{C}$ decade $^{-1}$ over the Northeast China, respectively. As a result, the DTR showed a significant declining trend of $-0.22^{\circ} \mathrm{C}$ decade $^{-1}$ during the same period.

For both urban and rural stations, the temporal changes of temperatures also had a great difference before and after 1990 (Figs. 5 and 6). But the average trends of temperatures in urban and rural stations were different during the study period (Table 2). During 1960 - 1989, both urban and rural stations showed a weak change of Tmax but a significant warming trend in Tmin. The minimum temperature increased much faster in urban areas $\left(0.48^{\circ} \mathrm{C}\right.$ decade $\left.^{-1}\right)$ than in rural areas $\left(0.31^{\circ} \mathrm{C}\right.$ decade $\left.{ }^{-1}\right)$, resulting in a greater decrease of DTR in the urban areas. From 1990 to 2016, all the temperatures showed no significant changes in urban and rural areas. During the whole study period of 1960 2016, there were significant warming trends of temperatures in both urban and rural stations. The increasing trends of Tmean, Tmax, and Tmin were larger in urban stations $(0.32$, 0.20 , and $0.45^{\circ} \mathrm{C}$ decade $^{-1}$, respectively) than that in rural stations $\left(0.28,0.19\right.$, and $0.38^{\circ} \mathrm{C}$ decade $^{-1}$, respectively). For the DTR, it significantly decreased by -0.25 and $-0.19^{\circ} \mathrm{C}$ decade $^{-1}$ for urban and rural stations, respectively.

Consistent with previous studies (Tayanç and Toros 1997; Ren et al. 2008; Li et al. 2010, 2015; Wang et al. 2012), this study calculated the trends of "urban minus rural temperatures" to investigate the effects of urbanization on temperature changes in Northeast China. The results showed that there were significant increasing trends of urban minus rural $\mathrm{Tmax}\left(0.03^{\circ} \mathrm{C}\right.$ decade $\left.^{-1}\right)$ and urban minus rural Tmin $\left(0.18^{\circ} \mathrm{C}\right.$ decade $\left.^{-1}\right)$ from 1960 to 1989 (Table 2). By contrast, during 1990 - 2016, there were weak decreasing trend of urban minus rural Tmax $\left(-0.01^{\circ} \mathrm{C}\right.$ decade $\left.^{-1}\right)$ and significant increasing trend of urban minus rural Tmin 0.03 (in units of ${ }^{\circ} \mathrm{C}$ decade ${ }^{-1}$ ) (Table 2). During the study period of 1960 - 2016, due to larger warming trends of temperatures in urban stations than that in rural temperatures, urban minus rural mean temperature showed a significant increasing trend $\left(0.04^{\circ} \mathrm{C}\right.$ decade $\left.^{-1}\right)$ in Northeast China. To further compare the temperature differences between urban and rural stations, we calculated the correlation coefficients between the populations and surface air temperatures (Tmean, Tmax, Tmin, and DTR) of the 60 stations in Northeast China during the study period (Table 3 ). The results showed that there were similar relationships of populations with long-term average annual temperatures and trends of annual temperatures. We found significant positive relationships of populations with Tmax and Tmin during 1960 - 1989. By contrast, there were weak negative correlations between populations and Tmax, but significant positive correlations between populations with Tmin during 1990 - 2016 (Table 3). During the study period of 1960 - 2016, there were significant positive relationships of populations with Tmean, Tmax, and Tmin, but negative correlations between populations and DTR.

\section{DISCUSSION}

It is well known that the increasing greenhouse gas concentrations mainly account for the warming global air temperatures during the last century (Wang and Dickinson 2013). Due to the impact of the greenhouse effect, temperatures in both the daytime and night-time showed significant warming trends in Northeast China during 1960 - 2016. Besides the greenhouse gases, solar radiation is regarded as another key factor affecting the temperatures in China (Shen et al. 2014). Different from the greenhouse gas that can influence 


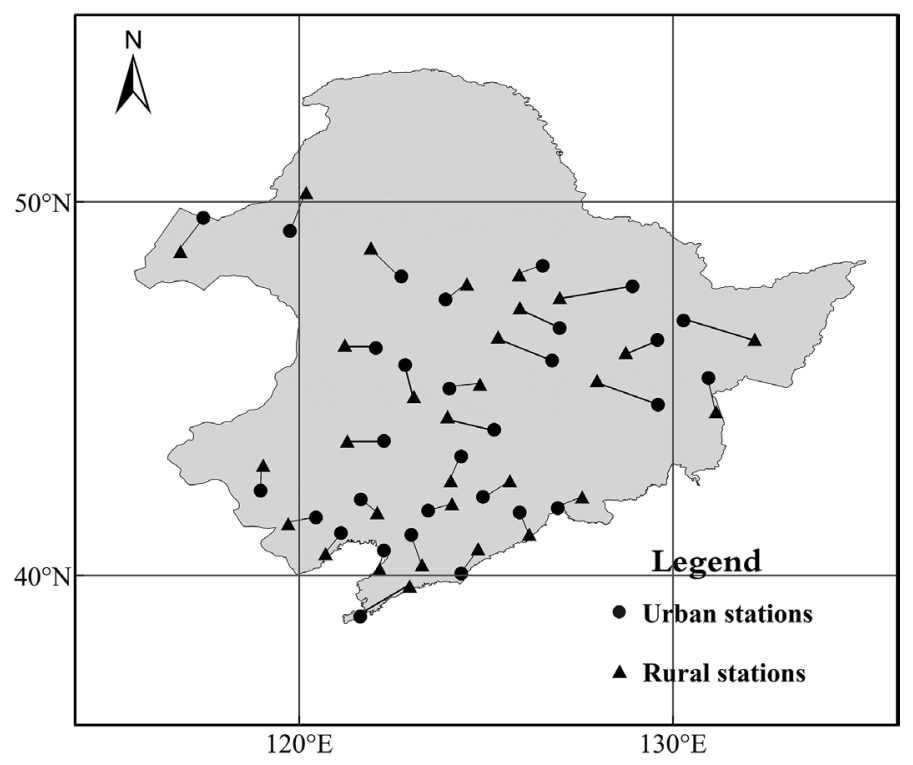

Fig. 1. Locations of the Northeast China and 30 pairs of urban and rural weather stations.

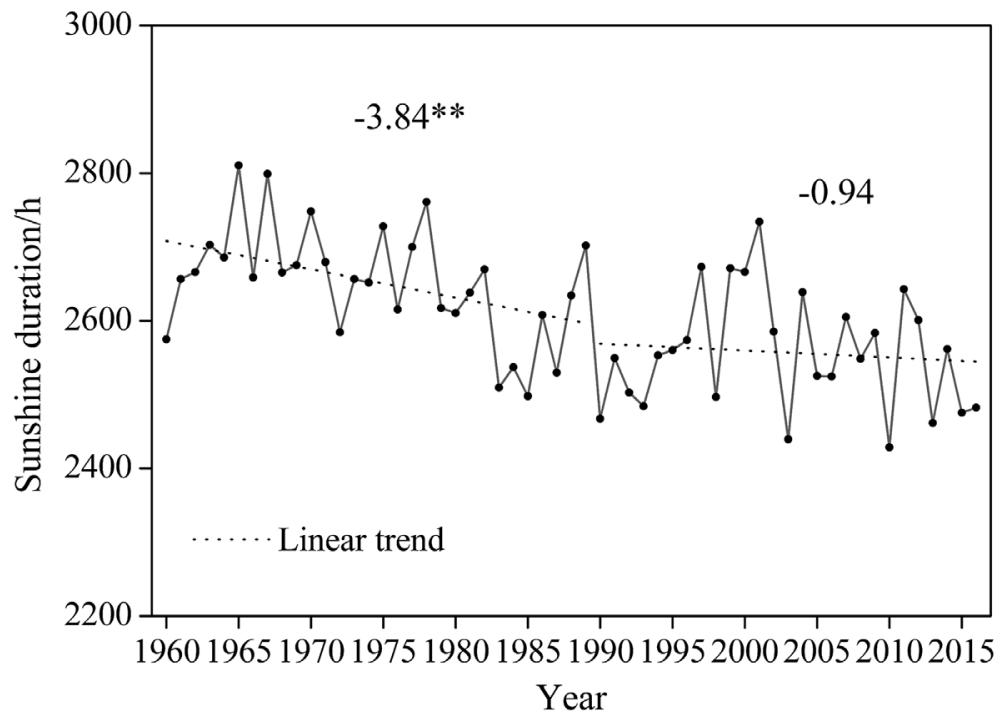

Fig. 2. Time series of annual average sunshine duration over the Northeast China from 1960 to 2016.

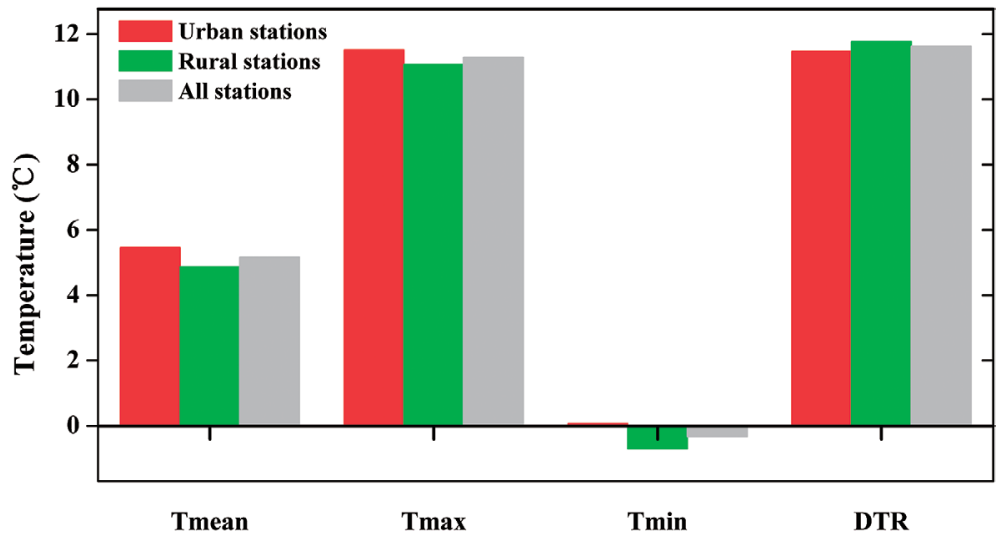

Fig. 3. Long-term average annual Tmean, Tmax, Tmin, and DTR $\left({ }^{\circ} \mathrm{C}\right)$ for urban and rural stations from 1960 to 2016. 
Table 1. Long-term average annual Tmean, Tmax, Tmin, and DTR $\left({ }^{\circ} \mathrm{C}\right)$ for urban and rural stations during two different periods of 1960 - 2016.

\begin{tabular}{c|cccc}
\hline Different study periods & Temperatures & Urban & Rural & Urban minus rural \\
\hline \multirow{4}{*}{$1960-1989$} & Tmean & 4.95 & 4.41 & 0.54 \\
& Tmax & 11.16 & 10.73 & 0.43 \\
& Tmin & -0.64 & -1.31 & 0.67 \\
& DTR & 11.81 & 12.04 & -0.23 \\
\hline \multirow{5}{*}{$1990-2016$} & Tmean & 6.02 & 5.41 & 0.61 \\
& Tmax & 11.90 & 11.45 & 0.45 \\
& Tmin & 0.81 & -0.01 & 0.82 \\
& DTR & 11.10 & 11.47 & -0.37 \\
\hline
\end{tabular}

(a)

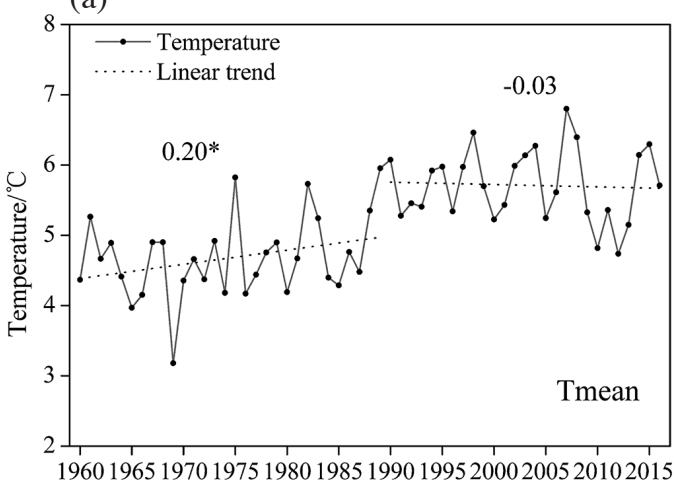

Year

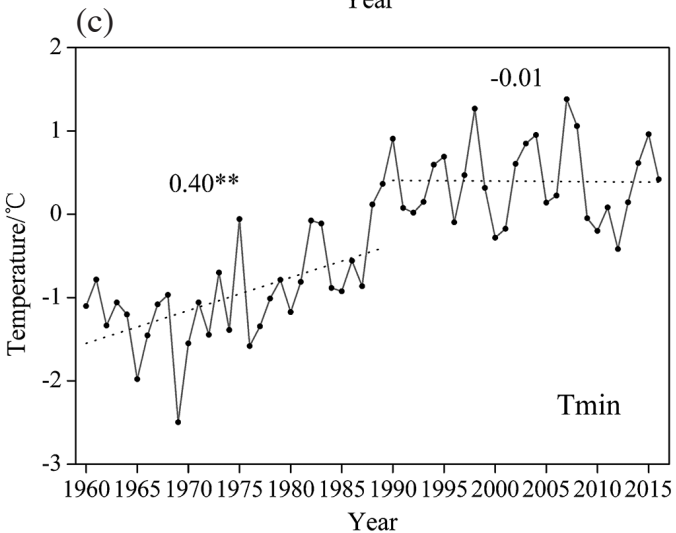

(b)

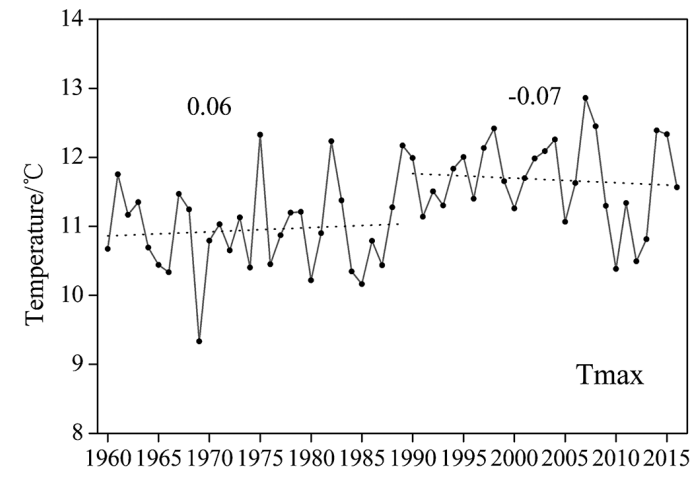

Year

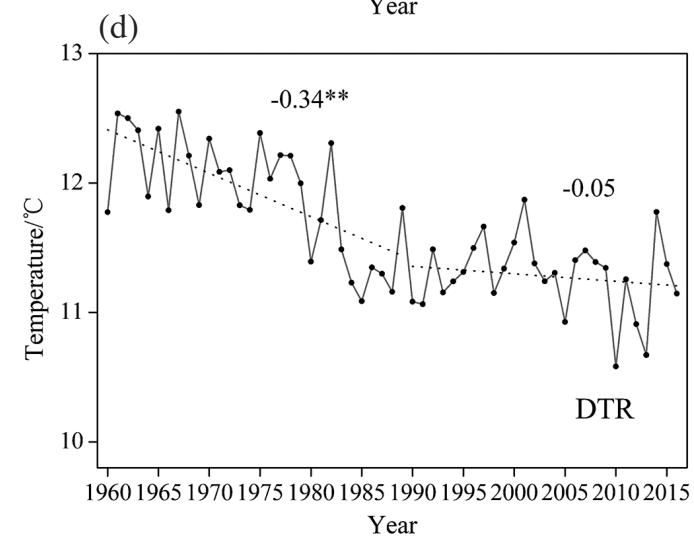

Fig. 4. Time series of regional average annual Tmean (a), Tmax (b), Tmin (c), and DTR (d) over the Northeast China from 1960 to 2016. 
(a)

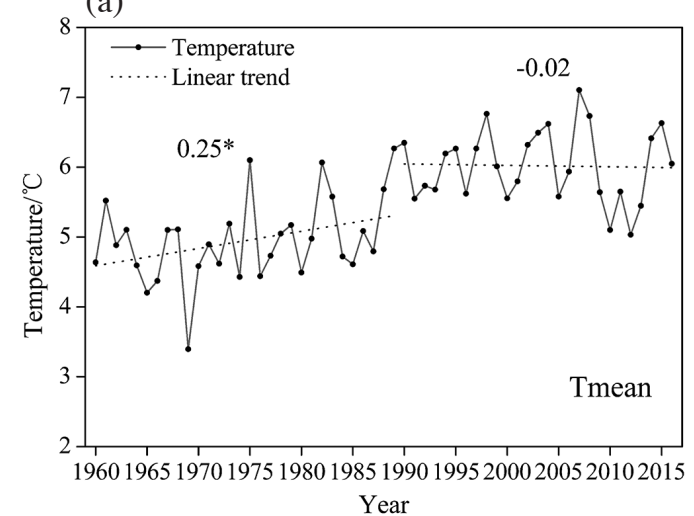

(c)

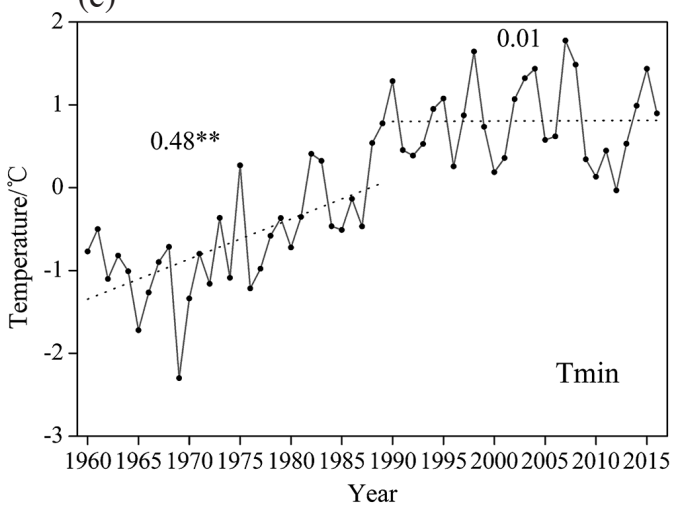

(b)

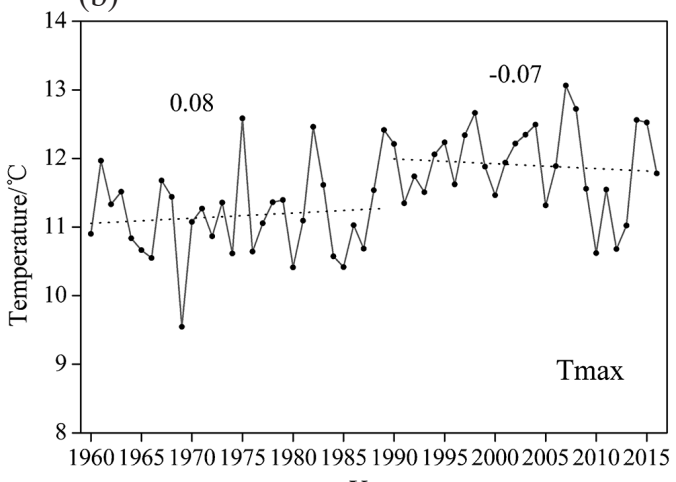

Year

(d)

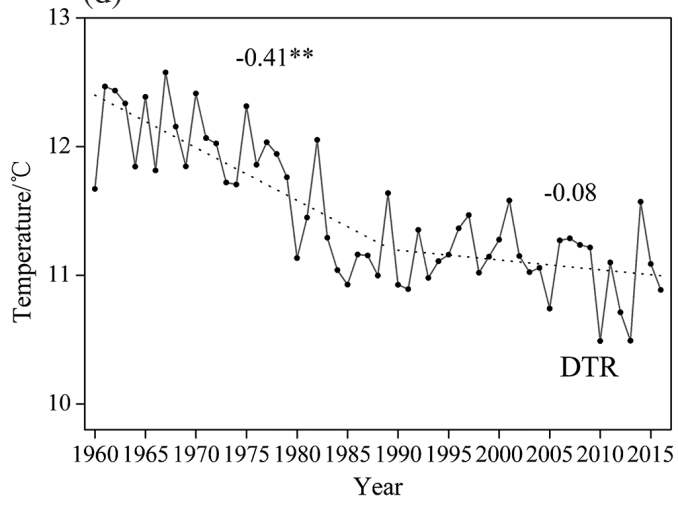

Fig. 5. Same with Fig. 4 but for urban stations.

(a)

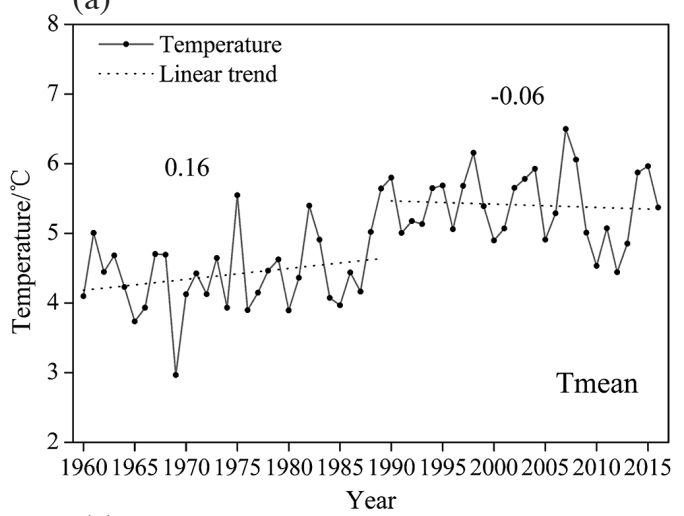

(c)

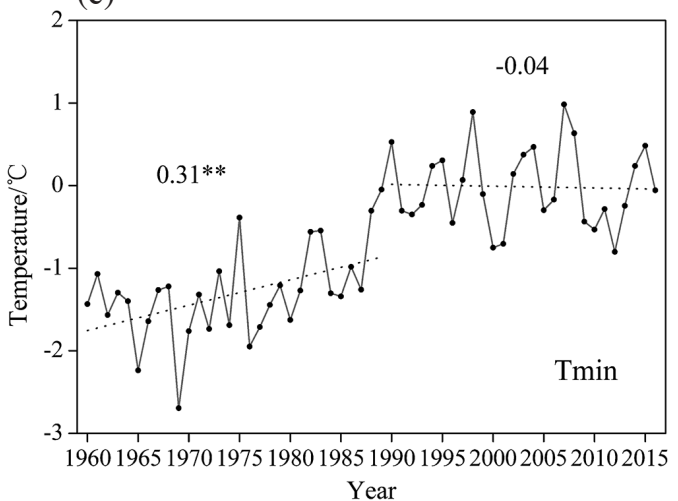

(b)

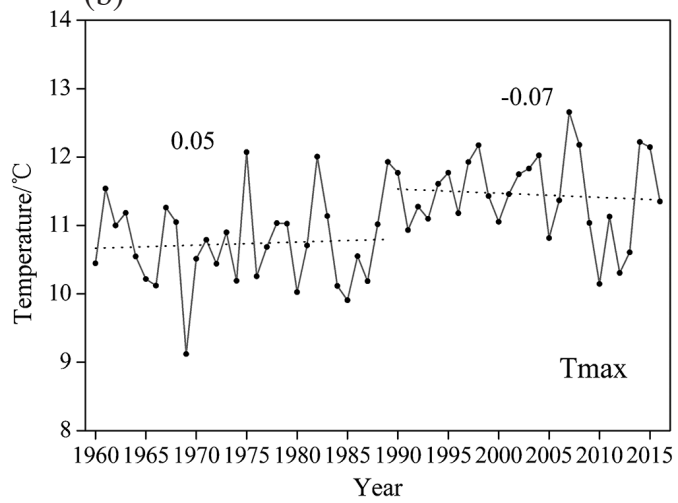

(d)

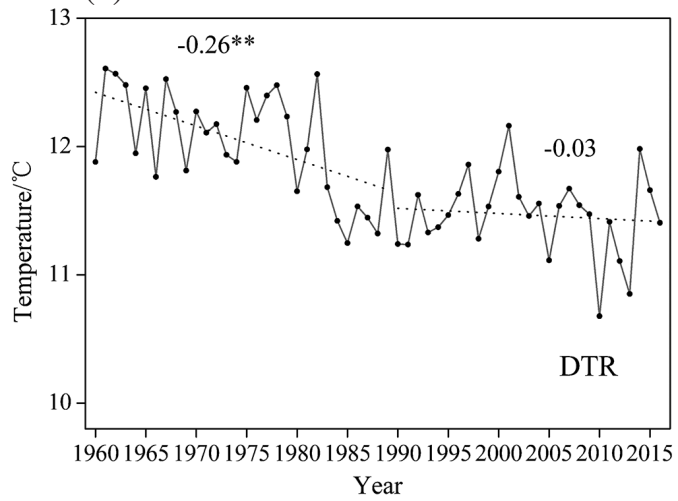

Fig. 6. Same with Fig. 4 but for rural stations. 
Table 2. Decadal trends of Tmean, Tmax, Tmin, and DTR $\left({ }^{\circ} \mathrm{C}\right.$ decade $\left.{ }^{-1}\right)$ for urban and rural stations during 1960 - 2016.

\begin{tabular}{c|cccc}
\hline Different study periods & Temperatures & Urban & Rural & Urban minus rural \\
\hline \multirow{3}{*}{$1960-2016$} & Tmean & $0.32^{* *}$ & $0.28^{* *}$ & $0.04^{* *}$ \\
& Tmax & $0.20^{* *}$ & $0.19^{* *}$ & $0.01^{*}$ \\
& Tmin & $0.45^{* *}$ & $0.38^{* *}$ & $0.07^{* *}$ \\
& DTR & $-0.25^{* *}$ & $-0.19^{* *}$ & $-0.06^{* *}$ \\
\hline \multirow{5}{*}{$1960-1989$} & Tmean & $0.25^{*}$ & 0.16 & $0.09^{* *}$ \\
& Tmax & 0.08 & 0.05 & $0.03^{*}$ \\
& Tmin & $0.48^{* *}$ & $0.31^{* *}$ & $0.18^{* *}$ \\
& DTR & $-0.41^{* *}$ & $-0.26^{* *}$ & $-0.15^{* *}$ \\
\hline \multirow{5}{*}{$1990-2016$} & Tmean & -0.02 & -0.06 & 0.03 \\
& Tmax & -0.07 & -0.07 & -0.01 \\
& Tmin & 0.01 & -0.04 & $0.03^{*}$ \\
& DTR & -0.08 & -0.03 & -0.04 \\
\hline
\end{tabular}

Note: * Significant at the 0.05 level. ** Significant at the 0.01 level.

Table 3. Correlation coefficients between the populations and surface air temperatures (Tmean, Tmax, Tmin, and DTR) of the 60 stations in Northeast China during the study period.

\begin{tabular}{c|ccc}
\hline Different study periods & Temperatures & $\begin{array}{c}\text { Correlations between the populations and } \\
\text { long-term average annual temperatures }\end{array}$ & $\begin{array}{c}\text { Correlations between the populations and } \\
\text { trends of annual temperatures }\end{array}$ \\
\hline \multirow{3}{*}{$1960-2016$} & Tmean & $0.30^{*}$ & $0.32^{* *}$ \\
& Tmax & $0.25^{*}$ & $0.26^{*}$ \\
& Tmin & $0.32^{* *}$ & $0.38^{* *}$ \\
& DTR & $-0.35^{* *}$ & $-0.30^{*}$ \\
\hline \multirow{3}{*}{$1960-1989$} & Tmean & $0.29^{*}$ & $0.27^{*}$ \\
& Tmax & $0.25^{*}$ & $0.25^{*}$ \\
& Tmin & $0.31^{*}$ & $0.38^{* *}$ \\
& DTR & $-0.33^{* *}$ & $-0.25^{*}$ \\
\hline \multirow{5}{*}{$1990-2016$} & Tmean & 0.21 & 0.20 \\
& Tmax & -0.13 & -0.09 \\
& Tmin & $0.33^{* *}$ & $0.30^{*}$ \\
& DTR & -0.16 & -0.08 \\
\hline
\end{tabular}

Note: * Significant at the 0.05 level. ** Significant at the 0.01 level. 
both Tmax and Tmin, solar radiation only has direct effect on Tmax during the daytime. Our results showed that the SD in the Northeast China significantly decreased from 1960 to 1989, but reached a stable level since 1990 (Fig. 2). The different changes of SD in Northeast China account for the different regimes of temperature changes before and after 1990. During 1960 - 1989, the significant declining of SD resulted in a larger increasing rate of Tmin than Tmax (Shen et al. 2014). From 1990 to 2016, both Tmax and Tmin experienced a warming hiatus under the effects of atmospheric circulation changes (Li et al. 2015; Shen et al. 2018). Due to no significant change of SD, there were comparable change trends of Tmax and Tmin in Northeast China during 1990 - 2016.

To investigate the effects of urbanization on temperature changes in Northeast China, this study calculated the trends of urban minus rural temperatures by comparing the temperatures in urban stations with their surrounding rural stations. The increasing (or decreasing) trend of urban minus rural temperature indicates the warming (or cooling) effect of urbanization on temperature in Northeast China (Ren et al. 2008). During the whole study period of 1960 - 2016, the increasing trends of urban minus rural temperatures indicate that the urbanization possibly had a significant warming effect on both Tmax and Tmin. These warming effects of urbanization on Tmax and Tmin were further confirmed by the significant positive correlations between the populations and Tmax and Tmin of the 60 stations in Northeast China during 1960 - 2016 (Table 3). The warming effect of urbanization on $\operatorname{Tmin}\left(0.07^{\circ} \mathrm{C}\right.$ decade $\left.^{-1}\right)$ was much larger than that on $\operatorname{Tmax}\left(0.01^{\circ} \mathrm{C}\right.$ decade $\left.^{-1}\right)$, resulting in an obvious decrease effect on DTR $\left(-0.06^{\circ} \mathrm{C}\right.$ decade $\left.^{-1}\right)$. It confirms that urban heat island effect is more obvious during the night.

During two different periods, we found that the different changes of SD before and after 1990 resulted in different effects of urbanization on temperatures in Northeast China. Compared with the rural stations, urban stations showed much faster increase of Tmin from 1960 to 1989 (Table 2). This phenomenon is closely related to the urbanization effect. On one hand, urban anthropogenic aerosols can cause more atmospheric counter radiation during the nighttime, which has obvious warming effect on the Tmin (Wang et al. 2012). On the other hand, thermal release from the impermeable land during the nighttime may also partly account for the faster increase of Tmin in urban areas. In terms of Tmax changes, the urban minus rural Tmax showed moderate but significant increase $\left(0.03^{\circ} \mathrm{C}\right.$ decade $\left.^{-1}\right)$ during 1960 1989 , suggesting that urbanization similarly had a warming effect on the Tmax during the daytime. This may be related to the reduced wind speed and more heat absorbed in urban areas (Kalnay and Cai 2003; Jusuf et al. 2007; Rizwan et al. 2008). Because of larger warming effect on Tmin, the urbanization had a decrease effect on DTR in the Northeast China (Table 2). Although many studies reported that urbanization tended to decrease Tmax during the daytime because of urban-enhanced aerosols (Kalnay and Cai 2003), our results showed a warming effect of urbanization on Tmax. It seems that the cooling effect of urban-enhanced aerosols on Tmax was not obvious when the SD significantly decreased in both urban and rural areas of Northeast China.

During 1990 - 2016, the significant warming effect of urbanization on temperatures was only found in Tmin, and the urban minus rural Tmax even showed a weak decreasing trend (Table 2). As a result, the urban minus rural Tmean and DTR showed no significant increasing $\left(0.04^{\circ} \mathrm{C}\right.$ decade $\left.^{-1}\right)$ and decreasing $\left(-0.04^{\circ} \mathrm{C}\right.$ decade $\left.{ }^{-1}\right)$ trend, respectively (Table 2$)$. Similar to the period of $1960-1989$, the warming effect on Tmin reflected the urban heat island effect during the nighttime. Contrary to the period of $1960-1989$, the urbanization has a cooling effect on Tmax $\left(-0.01^{\circ} \mathrm{C}\right.$ decade $\left.^{-1}\right)$ during 1990 - 2016. These different effects of urbanization on Tmax and Tmin were also reflected in the different correlations between the populations and Tmax and Tmin of the 60 stations in Northeast China during 1990 - 2016 (Table 3). It implies that the negative effects of urban-enhanced aerosols on Tmax began to become obvious when the SD showed no significant change in both urban and rural areas. By shading the surface from solar flux, more aerosols induced by urbanization had a cooling effect on the Tmax during the solar stable period. In addition, this weak cooling of temperature during the daytime could continually affect the temperature during the night-time, partly explaining the weak warming Tmin in urban areas.

It should be noted that there are some limitations in this study. First, current study did not use the specific data of urbanization or aerosol to investigate the effect of urbanization on temperatures in Northeast China. In order to accurately analyze the urbanization effect on temperatures in Northeast China, it is necessary to quantify the level of urbanization (e.g., the proportion of impervious land cover) and to use the data of aerosol concentrations. Second, urbanization is a dynamic process and there is a distinct difference between urbanization trend effects in areas that have been developed for a long time and those under rapid development. Although most previous studies, as well as this study, attributed the temperature differences between urban and rural station to urbanization effect, the temperature differences could be affected by some other factors such as topography and geography. Therefore, further study is still needed to investigate how much effect the urbanization has had on the variations of temperatures in Northeast China.

\section{CONCLUSION}

This study analyzed the changes of temperatures and the effects of urbanization on temperature change in Northeast China. Considering the complex effects of solar radiation changes on temperatures, this work emphatically compared the effects of urbanization on temperature changes 
during the different periods of solar radiation changes. Based on the trends of urban minus rural temperatures, we concluded that urbanization in Northeast China possibly had a significant warming effect on Tmin during the nighttime, but had different effects on Tmax under the different changes of solar radiation. There were moderate warming effects of urbanization on Tmax during the solar dimming period of 1960 - 1989, but weak cooling effects on Tmax during the solar stable period after 1990. Due to obvious warming effect of urbanization on Tmin, urbanization in Northeast China tends to result in an increase of Tmean but a decrease of DTR during 1960 - 2016, respectively.

Acknowledgements We thank China Meteorological Administration for providing the meteorological data. This study was funded by the National Natural Science Foundation of China (No. 41971065), the Outstanding Young Talent Fund Project of Jilin Province (20190103013JH), the Youth Innovation Promotion Association of CAS (2019235), and the National Key Research and Development Program of China (2017YFC0212303).

\section{REFERENCES}

Cao, C., X. Lee, S. Liu, N. Schultz, W. Xiao, M. Zhang, and L. Zhao, 2016a: Urban heat islands in China enhanced by haze pollution. Nat. Comm., 7, doi: 10.1038/ ncomms12509. [Link]

Cao, Q., D. Yu, M. Georgescu, and J. Wu, 2016b: Impacts of urbanization on summer climate in China: An assessment with coupled land-atmospheric modeling. J. Geophys. Res., 121, 10505-10521, doi: 10.1002/2016JD025210. [Link]

Chen, L. and O. W. Frauenfeld, 2016: Impacts of urbanization on future climate in China. Clim. Dyn., 47, 345357, doi: 10.1007/s00382-015-2840-6. [Link]

Dai, A., A. D. Del Genio, and I. Y. Fung, 1997: Clouds, precipitation and temperature range. Nature, 386, 665666, doi: 10.1038/386665b0. [Link]

Dai, A., K. E. Trenberth, and T. R. Karl, 1999: Effects of clouds, soil moisture, precipitation, and water vapor on diurnal temperature range. J. Clim., 12, 2451-2473, doi: 10.1175/1520-0442(1999)012<2451:EOCSMP >2 .0.CO;2. [Link]

Du, H., Z. Wu, M. Li, Y. Jin, S. Zong, and X. Meng, 2013: Characteristics of extreme daily minimum and maximum temperature over Northeast China, 1961-2009. Theor. Appl. Climatol., 111, 161-171, doi: 10.1007/ s00704-012-0649-3. [Link]

Easterling, D. R., B. Horton, P. D. Jones, T. C. Peterson, T. R. Karl, D. E. Parker, M. J. Salinger, V. Razuvayev, N. Plummer, P. Jamason, and C. K. Folland, 1997: Maximum and minimum temperature trends for the globe. Science, 277, 364-367, doi: 10.1126/sci- ence.277.5324.364. [Link]

Hansen, J., R. Ruedy, M. Sato, and K. Lo, 2010: Global surface temperature change. Rev. Geophys., 48, RG4004, doi: 10.1029/2010RG000345. [Link]

Hua, L. J., Z. G. Ma, and W. D. Guo, 2008: The impact of urbanization on air temperature across China. Theor. Appl. Climatol., 93, 179-194, doi: 10.1007/s00704007-0339-8. [Link]

Jones, P. D., P. Y. Groisman, M. Coughlan, N. Plummer, W.-C. Wang, and T. R. Karl, 1990: Assessment of urbanization effects in time series of surface air temperature over land. Nature, 347, 169-172, doi: 10.1038/347169a0. [Link]

Jusuf, S. K., N. H. Wong, E. Hagen, R. Anggoro, and Y. Hong, 2007: The influence of land use on the urban heat island in Singapore. Habitat International, 31, 232-242, doi: 10.1016/j.habitatint.2007.02.006. [Link]

Kalnay, E. and M. Cai, 2003: Impact of urbanization and land-use change on climate. Nature, $\mathbf{4 2 3}, 528-531$, doi: 10.1038/nature01675. [Link]

Karl, T. R., P. D. Jones, R. W. Knight, G. Kukla, N. Plummer, V. Razuvayev, K. P. Gallo, J. Lindseay, R. J. Charlson, and T. C. Peterson, 1993: A new perspective on recent global warming: Asymmetric trends of daily maximum and minimum temperature. Bull. Amer. Meteorol. Soc., 74, 1007-1024, doi: 10.1175/1520-0477(1993)074<1007:ANPORG>2.0. CO;2. [Link]

Kendall, M. G., 1975: Rank Correlation Measures, Charles Griffin, London.

Li, Q., H. Zhang, X. Liu, and J. Huang, 2004: Urban heat island effect on annual mean temperature during the last 50 years in China. Theor. Appl. Climatol., 79, 165-174, doi: 10.1007/s00704-004-0065-4. [Link]

Li, Q., W. Li, P. Si, G. Xiaorong, W. Dong, P. Jones, J. Huang, and L. Cao, 2010: Assessment of surface air warming in northeast China, with emphasis on the impacts of urbanization. Theor. Appl. Climatol., 99, 469478, doi: 10.1007/s00704-009-0155-4. [Link]

Li, Q., S. Yang, W. Xu, X. L. Wang, P. Jones, D. Parker, L. Zhou, Y. Feng, and Y. Gao, 2015: China experiencing the recent warming hiatus. Geophys. Res. Lett., 42, 889-898, doi: 10.1002/2014GL062773. [Link]

Liu, B., M. Xu, M. Henderson, Y. Qi, and Y. Li, 2004: Taking China's temperature: Daily range, warming trends, and regional variations, 1955-2000. J. Clim., 17, 44534462, doi: 10.1175/3230.1. [Link]

Mann, H. B., 1945: Nonparametric tests against trend. Econometrica, 13, 245-259, doi: 10.2307/1907187. [Link]

Portman, D. A., 1993: Identifying and correcting urban bias in regional time series: Surface temperature in China's northern plains. J. Clim., 6, 2298-2308, doi: 10.1175/1520-0442(1993)006<2298:IACUBI>2.0 . CO;2. [Link] 
Ren, G., Y. Zhou, Z. Chu, J. Zhou, A. Zhang, J. Guo, and X. Liu, 2008: Urbanization effects on observed surface air temperature trends in North China. J. Clim., 21, 13331348, doi: 10.1175/2007JCLI1348.1. [Link]

Ren, W., Y. Geng, B. Xue, T. Fujita, Z. Ma, and P. Jiang, 2012: Pursuing co-benefits in China's old industrial base: A case of Shenyang. Urban Climate, 1, 55-64, doi: 10.1016/j.uclim.2012.07.001. [Link]

Rizwan, A. M., L. Y. C. Dennis, and C. Liu, 2008: A review on the generation, determination and mitigation of Urban Heat Island. J. Environ. Sci., 20, 120-128, doi: 10.1016/S1001-0742(08)60019-4. [Link]

Shen, X., B. Liu, G. Li, Z. Wu, Y. Jin, P. Yu, and D. Zhou, 2014: Spatiotemporal change of diurnal temperature range and its relationship with sunshine duration and precipitation in China. J. Geophys. Res., 119, 1316313179, doi: 10.1002/2014JD022326. [Link]

Shen, X., B. Liu, and D. Zhou, 2017: Spatiotemporal changes in the length and heating degree days of the heating period in Northeast China. Meteorol. Appl., 24, 135141, doi: 10.1002/met.1612. [Link]

Shen, X., B. Liu, and X. Lu, 2018: Weak Cooling of Cold Extremes Versus Continued Warming of Hot Extremes in China During the Recent Global Surface Warming Hiatus. J. Geophys. Res., 123, 4073-4087, doi: 10.1002/2017JD027819. [Link]

Shen, X., B. Liu, Z. Xue, M. Jiang, X. Lu, and Q. Zhang, 2019a: Spatiotemporal variation in vegetation spring phenology and its response to climate change in freshwater marshes of Northeast China. Sci. Total Environ., 666, 1169-1177, doi: 10.1016/j.scitotenv .2019.02.265. [Link]

Shen, X., Z. Xue, M. Jiang, and X. Lu, 2019b: Spatiotemporal change of vegetation coverage and its relationship with climate change in freshwater marshes of Northeast China. Wetlands, 39, 429-439, doi: 10.1007/ s13157-018-1072-z. [Link]

Shi, G.-Y., T. Hayasaka, A. Ohmura, Z.-H. Chen, B. Wang, J.-Q. Zhao, H.-Z. Che, and L. Xu, 2008: Data quality assessment and the long-term trend of ground solar radiation in China. J. Appl. Meteorol. Climatol., 47, 1006-1016, doi: 10.1175/2007JAMC1493.1. [Link]

Su, Y., X. Chen, Y. Li, J. Liao, Y. Ye, H. Zhang, N. Huang, and Y. Kuang, 2014: China's 19-year city-level carbon emissions of energy consumptions, driving forces and regionalized mitigation guidelines. Renew. Sustain. Energ. Rev., 35, 231-243, doi: 10.1016/j. rser.2014.04.015. [Link]

Sun, L., B. Shen, Z. Gao, B. Sui, L. Bai, S.-H. Wang, G. An, and J. Li, 2007: The impacts of moisture transport of East Asian monsoon on summer precipitation in Northeast China. Adv. Atmos. Sci., 24, 606-618, doi: 10.1007/s00376-007-0606-8. [Link]

Sun, Y., X. Zhang, G. Ren, F. W. Zwiers, and T. Hu,
2016: Contribution of urbanization to warming in China. Nat. Clim. Change, 6, 706-709, doi: 10.1038/ NCLIMATE2956. [Link]

Tang, W.-J., K. Yang, J. Qin, C. C. K. Cheng, and J. He, 2011: Solar radiation trend across China in recent decades: A revisit with quality-controlled data. Atmos. Chem. Phys., 11, 393-406, doi: 10.5194/acp-11-3932011. [Link]

Tayanç, M. and H. Toros, 1997: Urbanization effects on regional climate change in the case of four large cities of Turkey. Clim. Change, 35, 501-524, doi: 10.1023/A:1005357915441. [Link]

Wang, J., Z. Yan, Z. Li, W. Liu, and Y. Wang, 2013: Impact of urbanization on changes in temperature extremes in Beijing during 1978-2008. Chin. Sci. Bull., 58, 46794686, doi: 10.1007/s11434-013-5976-y. [Link]

Wang, J. X. L. and D. J. Gaffen, 2001: Late-twentieth-century climatology and trends of surface humidity and temperature in China. J. Clim., 14, 2833-2845, doi: 10.1175/1520-0442(2001)014<2833:LTCCAT>2.0 . $\mathrm{CO} ; 2$. [Link]

Wang, K. and R. E. Dickinson, 2013: Contribution of solar radiation to decadal temperature variability over land. Proc. Natl. Acad. Sci., 110, 14877-14882, doi: 10.1073/pnas.1311433110. [Link]

Wang, K., H. Ye, F. Chen, Y. Xiong, and C. Wang, 2012: Urbanization effect on the diurnal temperature range: Different roles under solar dimming and brightening. J. Clim., 25, 1022-1027, doi: 10.1175/JCLID-10-05030.1. [Link]

Wang, W.-C., Z. Zeng, and T. R. Karl, 1990: Urban heat islands in China. Geophys. Res. Lett., 17, 2377-2380, doi: 10.1029/GL017i013p02377. [Link]

Wild, M., A. Ohmura, and K. Makowski, 2007: Impact of global dimming and brightening on global warming. Geophys. Res. Lett., 34, doi: 10.1029/2006GL028031. [Link]

Yang, X., Y. Hou, and B. Chen, 2011: Observed surface warming induced by urbanization in east China. $J$. Geophys. Res., 116, doi: 10.1029/2010JD015452. [Link]

Ye, J., F. Li, G. Sun, and A. Guo, 2010: Solar dimming and its impact on estimating solar radiation from diurnal temperature range in China, 1961-2007. Theor. Appl. Climatol., 101, 137-142, doi: 10.1007/s00704-0090213-y. [Link]

Zhang, P., 2008: Revitalizing old industrial base of Northeast China: Process, policy and challenge. Chin. Geogr. Sci., 18, 109-118, doi: 10.1007/s11769-0080109-2. [Link]

Zhou, L., R. E. Dickinson, Y. Tian, J. Fang, Q. Li, R. K. Kaufmann, C. J. Tucker, and R. B. Myneni, 2004: Evidence for a significant urbanization effect on climate in China. Proc. Natl. Acad. Sci., 101, 9540-9544, doi: 
10.1073/pnas.0400357101. [Link $]$

Zhou, L., A. Dai, Y. Dai, R. S. Vose, C.-Z. Zou, Y. Tian, and H. Chen, 2009: Spatial dependence of diurnal tem- perature range trends on precipitation from 1950 to 2004. Clim. Dyn., 32, 429-440, doi: 10.1007/s00382008-0387-5. [Link] 